\title{
3 Boyutlu Yazıcı ile Üretilen Parça Yüzeylerini Toz Kaplama ve Kaplama Eroziv Aşınma Davranışlarının Karakterizasyonu
}

\author{
Ahmet Sevil ${ }^{1}$, Ahmet Ondört ${ }^{2}$, Satılmış Ürgün ${ }^{3}$, Sinan Fidan ${ }^{41}$ \\ ${ }^{1}$ Kocaeli Üniversitesi, Havacılık ve Uzay Bilimleri Fakültesi, Uçak Elektrik-Elektronik Bakım Bölümü, Kocaeli, Türkiye, (ORCID: 0000-0002-8739-4297) \\ ${ }^{2}$ Kocaeli Üniversitesi, Havacılık ve Uzay Bilimleri Fakültesi, Uçak Elektrik-Elektronik Bakım Bölümü, Kocaeli, Türkiye, (ORCID: 0000-0002-5641-4654) \\ ${ }^{3}$ Kocaeli Üniversitesi, Havacılık ve Uzay Bilimleri Fakültesi, Uçak Elektrik-Elektronik Bakım Bölümü, Kocaeli, Türkiye, (ORCID: 0000-0003-3889-6909) \\ ${ }^{4}$ Kocaeli Üniversitesi, Havacılık ve Uzay Bilimleri Fakültesi, Uçak Gövde-Motor Bakım Bölümü, Kocaeli, Türkiye, (ORCID: 0000-0003-4385-4981)
}

(İlk Geliş Tarihi 29 Kasım 2019 ve Kabul Tarihi 31 Aralık 2019)

(DOI: $10.31590 /$ ejosat.652512)

ATIF/REFERENCE: Sevil, A., Ondört, A., Ürgün, S. \& Fidan, S. (2019). 3 Boyutlu Yazıcı ile Üretilen Parça Yüzeylerini Toz Kaplama ve Kaplama Eroziv Aşınma Davranışlarının Karakterizasyonu. Avrupa Bilim ve Teknoloji Dergisi, (17), Xx-Xx.

$\ddot{O} z$

Günümüzde 3 boyutlu (3D) yazıcılarla parça üretimi giderek artan oranda kullanılan bir yöntem haline gelmektedir. 3D yazıcılarla üretilen parçalarda hammadde olarak polilaktik asit (PLA) filamantler kullanılmaktadır. PLA malzemeden üretilmiş parçaların servis şartları altında yüzey çizilmelerine dayanımı düşük olabilmektedir. 3D yazıcılarla üretilmiş parçaların yüzey çizilmelerine dayanımını artırmak amacıyla bu çalışmada üretilen silindirik parçanın yüzeyi üç farklı toz ve epoksi reçine kullanılarak kaplanmıştır. Așınma dayanımını iyileştirmek amacıyla beyaz alümina, garnet ve seramik bilya tozları yüzey kaplamasında tercih edilmiştir. Kaplama işlemi için özel tasarlanıp imal edilen motorize bir düzenekle belirli devir sayısında döndürülen 3D imal edilmiş silindirik numune epoksi ve arkasından toz uygulamasıyla kaplanmıştır. Kaplama işlemi sonrası yüzey pürüzlülük analizleri gerçekleştirilmiştir. Pürüzlülük analizlerinde alansal taramalar yapılarak ortalama alansal pürüzlülük değerleri $\left(\mathrm{S}_{\mathrm{a}}\right)$ irdelenmiştir. Alansal pürüzlülük değerleri tozların kaplama esnasında yüzeye yapışma karakteristiği ve yüzeyde tozların dağılımı hakkında da önemli bilgiler vermiştir. Yüzeyi kaplama sonrası yüzeyi partikül takviyeli kompozit haline gelen numuneler erozif aşınma testlerine maruz bırakılmıştır. Erozif aşınma testleri sonrası kütle kayıpları ve yüzey pürüzlülük analizleri gerçekleştirilerek aşınma dayanımı karakterizasyonu gerçekleştirilmiştir. Erozif sonrası yapılan yüzey analizlerinde kaplama tozlar ve aşındırıcı tozlar arası etkileşimin yüzey aşınma hasarına etkileri ortaya konmuştur. Uçak parçalarında sıkça ortaya çıkan yüksek hızlardaki eroziv aşınmanın, 3D yazıcılarla üretilmiş uçak parçalarında yüzeyde ne tür hasarlara sebep olabileceği konusunda yapılan çalışmayla bilgi birikimi sağlanmaya çalışılmıştır. Ayrıca 3D üretilen karmaşık geometrili parçaların yüzeylerini farklı bir metotla kaplama konusuna ihtiyaç bulunmaktadır. Sonuç olarak 3D imalatla üretilen komponentlerin yüzey kaplamasıyla ilgili alternatif bir yöntem denenmiş ve erozif aşınma dayanımına etkileri yüzey analizleri ile ortaya konulmaya çalışılmıştır.

Anahtar Kelimeler: 3 Boyutlu imalat, Kaplama, Aşınma, Pürüzlülük.

\section{Powder Coating of 3D Printed Parts Surfaces and Erosive Wear Behaviour Characterization of Coatings}

\begin{abstract}
Nowadays, the production of parts with 3D printers is becoming an increasingly used method. Polylactic acid (PLA) filaments are used as raw material in parts produced with 3D printers. Parts produced from PLA may have low scratch resistance under service conditions. In order to increase the resistance of parts produced by 3D printers to surface scratches, the surface of the cylindrical part produced in this study was coated with three different powder and epoxy resin. In order to improve the abrasion resistance, white alumina, garnet
\end{abstract}

\footnotetext{
${ }^{1}$ Sorumlu Yazar: Kocaeli Üniversitesi, Havacılık ve Uzay Bilimleri Fakültesi, Uçak Gövde-Motor Bakım Bölümü, Kocaeli, Türkiye, ORCID: 00000003-4385-4981, sfidan@kocaeli.edu.tr
} 
and ceramic ball powders are preferred for surface coating. A specially designed and manufactured motorized assembly for the coating process is rotated at a certain speed and the 3D manufactured cylindrical sample is coated with epoxy followed by powder application. Surface roughness analysis was performed after coating process. In the roughness analysis, the mean spatial roughness values (Sa) were examined. The spatial roughness values gave important information about the adhesion characteristics of the powders to the surface during coating and the distribution of the powders on the surface. After the surface coating, the specimens which became particle reinforced composite were subjected to erosive wear tests. After erosive wear tests, mass losses and surface roughness analyzes were performed and abrasion resistance characterization was performed. After erosive surface analysis, the effects of the interaction between coating powders and abrasive powders on surface wear damage were revealed. The aim of this study is to provide information about the possible damages on the surface of aircraft parts produced with 3D printers. In addition, there is a need for a different method of coating the surfaces of complex geometric parts produced in 3D. As a result, an alternative method of surface coating of components produced by 3D manufacturing has been tried and its effects on erosive abrasion resistance have been tried to be determined by surface analysis.

Keywords: 3D manufacturing, Coating, Wear, Roughness.

\section{Giriş}

Katmanlı üretim (additive manufacturing: AM) veya 3D baskı ile üretim, geleneksel üretime kıyasla birçok avantaj sunduğu için karmaşık bileşenler üretmek için mevcut teknoloji olarak hızla gelişmektedir (Bhaduri et al., 2017). Katmanlı üretim, daha fazla tasarım özgürlüğünün yanı sıra karmaşık iç ve dış yapılara sahip karmaşık parçaları verimli bir şekilde üretme yeteneğini de içerir (Bhaduri et al., 2017). Karmaşık parça üretiminin önemli olduğu havacılık, otomotiv ve biyomedikal gibi endsütrilerde 3D bask1 ile karmaşık geometrilerin üretiminde büyük oranda esneklik sağlanmaktadır. Üretim esnekliğinin büyük avantaja dönüştüğü 3D baskı yönteminin problemlerinden birisi seri üretimde üretim zamanın optimize edilmeye ihtiyaç duyması ve basılan parçaların yüzeylerinin dış etkilere dayanımının düşük olmasıdır. Üretilen parçalar servis şartları altında mekanik sürtünme, ultraviole 1şık, sıcaklık, nem, toz vb. etkilere maruz kaldıklarında parçanın güvenli çalışma ömrü büyük oranda düşmektedir. 3D basım ile üretilen parçaların servis ömürlerini uzatmak amacıyla, üretim sonrası yüzeylerine uygulanan koruyucu işlemlerin ve kpalamaların çeşitliliğini artırmak amacıyla son yıllarda çok sayıda çalışma yapılmaya başlanmıştır.

Bhaduri ve arkadaşları, 3D ile üretilmiş paslanmaz çelik malzemeden oluşan bir parçanın yüzeyini laserle cilalama işlemi gerçekleştirerek yüzey bütünlüğünü artırmayı hedeflemişlerdir (Bhaduri et al., 2017). Laserle cilalama işlemi sırasındaki işlem parametrelerini iyileştirerek en iyi yüzey kalitesi ve düşük yüzey pürüzlülüğünü elde etmeye çalışmışlardır. Laserle cilalama işlemindeki parametrelerini optimize ederek, yüzeyde herhangibir çizik, çukur, çatlak vb. oluşumlara neden olmadan numunenin alansal pürüzlülük değerinde \%94'lük bir azalmayı sağlamayı başarmışlardır (Bhaduri et al., 2017). Laserle cilalama işleminin etkinliğini etkileyen bir başka önemli faktörün de, 3D baskı ile üretim sonrası malzeme yüzeyinin ilk pürüzlülük değeri olduğu belirtilmiştir. Laserle cilalama işlemi sonrası yüzeyde oluşan renk yoğunluğunun da işlem esnasında oluaşn oksit tabakasının miktarına/derinliğine bağlı olduğu; dolayısıyla 3D baskı ile üretilmiş metal yüzeylerde laserle cilalama işleminin argon gazı altında yapılmasıyla yüzey oksidasyon tabakasının oluşmasının engellenebileceği belirtilmiştir (Bhaduri et al., 2017). Laserle cilalama işlemini takiben sertlikteki artış, yüzeyin aşınma direncini artırabilirken; yeniden erime nedeniyle alt yüzeyin yoğunlaşması, 3D baskı ile üretilen parçalarda doğal olan gözenekleri ortadan kaldırabilir. Bu yüzden, 3D baskı ile üretilen parçalarda gözeneksiz dış kabuk önemli ise; lazerle cilalama teknolojisinin çok önemli olduğu belirtilmiştir (Bhaduri et al., 2017).

Lanzetta ve Sachs yaptıkları çalışmayla 3D baskıyla elde edilen yüzeylerde çift modlu (bimodal) tozların kullanımının son kat yüzey pürüzlülüğünü iyileştirdiğini ortaya koymuşlardır (Lanzetta \& Sachs, 2003). 3B basılan parçalarda yüzey kalitesinin, daha ince tabakaların kullanılmasına izin verdiği ve ayrıca her tabaka içinde daha iyi bir yüzey kalitesi sağladığı için; çok ince tozlar kullanılarak büyük ölçüde iyileştirilebilir olduğunu söylemişlerdir (Lanzetta \& Sachs, 2003). Çalışmalarında, 3D baskı ile ürettikleri parçalarda

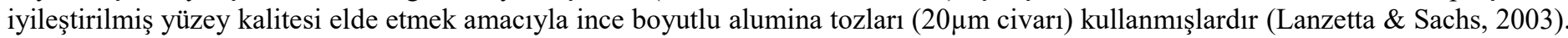
Sonuç olarak; 3D baskı işleminin altında yatan merkezi fiziksel etkileşimin, toz ve bağlayıcı madde etkileşimi olduğunu ayrıca bu etkileşimin 3D yazıcı ile üretilen parçalarda iyi yüzey kalitesi elde etmede önemli bir rolü olduğunu söylemişlerdir (Lanzetta \& Sachs, 2003). Çift modlu (bimodal) tozların 3D baskı yönteminde kullanılması sonucu özellikle yüzeyde oluşturdukları son tabakanın yüzey pürüzlülüğünü azalttığı sonucunu ortaya koymuşlar, bununla birlikte yüzeyde 3D baskı sırasındaki çift modlu tozdan ince partiküllerin yüzeyde dağılımının homojen olmasına rağmen baskı sonrası yüzeyde ince tanelerin yüzeyde toplanarak pürüzlülüğü azalttı̆̆ını söylemişlerdir (Lanzetta \& Sachs, 2003).

Kumar ve arkadaşları araştırmalarında, ticari olarak temin edilebilen 3D basılmış çeliklerin ve kompozitlerin, tribolojik performanslarının geleneksel Hardox 400 aşınmaya dayanıklı çelik ve AISI 316 paslanmaz çelik ile karşılaştırmasını gerçekleştirmişlerdir (Kumar, Antonov, Beste, \& Goljandin, 2020). Sonuçlarında, 3D yazıcıyla üretilen çeliklerin ve kompozitlerin referans malzemelerinkinden daha iyi aşınma direnci gösterdiğini söylemişlerdir (Kumar et al., 2020).

3D yazıcı ile üretilen parçaların toz malzemelerle kaplanması ile ilgili ve bu malzemelerin eroziv aşınma davranışlarıyla ilgili çalışma sayılarının az olması sebebiyle gerçekleştirilen çalışmada bu alana yönelinmiştir. Bununla birlikte, eroziv aşınma daha çok malzeme yüzeyinde hasar mekanizmaları ortaya çıkardığı için, pürüzülülük analizleri derinlemesine gerçekleştirilmeye çalışılmıştır. 


\section{Materyal ve Metot}

\section{1. Üç Boyutlu Yazııı ile Kaplama Yapılacak Parça İmalatı}

Kaplama yapmak üzere üç boyutlu yazıcı ile parça üretiminde polilaktikasit (PLA) filament malzemesi kullanılmıştır. PLA, 3 boyutlu yazıcılarda en yaygın olarak kullanılan, üretim esnasında zehirli atıklar ortaya çıkarmayan, işlem basamakları kolay optimize edilebilir ve ucuz bir malzeme olduğu için yaygın olarak tercih edilmektedir. Bu çalışmada kullanılan Esun marka PLA filamentin üreticinin deklare ettiği özellikleri Tablo 2.1 'de verilmiştir.

Tablo 2.1: PLA filamentin teknik özellikleri

\begin{tabular}{l|c|c}
\hline \multicolumn{1}{c|}{ PLA Özellik } & Birim & Değer \\
\hline Yoğunluk & $\mathrm{kg} / \mathrm{m}^{3}$ & $1.20-1.25$ \\
\hline Erime noktası & ${ }^{\circ} \mathrm{C}$ & $190-220$ \\
\hline Eriyik akı̧ indeksi & $\mathrm{gr} / 10$ dakika & 7.8 \\
\hline Gerilme dayanım gücü & $\mathrm{Mpa}$ & 62.63 \\
\hline Kopma anında uzama & $\%$ & 4.43 \\
\hline Eğilme mukavemeti & $\mathrm{Mpa}$ & 65.02 \\
\hline Eğilme modülü & $\mathrm{Mpa}$ & 2504.4 \\
\hline Darbe Dayanımı & $\mathrm{kJ} / \mathrm{m}^{2}$ & 4.28 \\
\hline Hassasiyet & $1.75 \mathrm{~mm}: 1.7-1.8 \mathrm{~mm}$ \\
\hline
\end{tabular}

Kaplama yapılacak test parçaları Zortrax M200 Plus ${ }^{\circledR}$ 3D printer ile üretilmiștir. Parçanın 3 boyutlu baskı için üretilmesinde CAD dosyası ile Z-Suite v2.2.0.0 yazıcı programı kullanılmış, parça üretimi esnasında tasarlanan stereolithography (STL) dosyası yazıcıya aktarılarak kullanılmıştır. Silindirik geometrideki kaplama yapılacak parçanın çapı $30 \mathrm{~mm}$ yüksekliği ise 63 mm olacak şekilde basılmıştır. Üç boyutlu baskı esnasında $0.19 \mathrm{~mm}$ tabaka kalınlığı seçilmiştir. Bu baskı kalınlığının seçilmesi ile birlikte maksimum dolgu ve yüksek kalitede yüzey oluşturma seçenekleri işaretlenerek yüksek kalitede parça üretimi hedeflenmiştir. Basma hızı 2100 mm/dak., X/y ekseninde baskı hızı 3300 mm/dak., Z ekseninde baskı hareket hızı 600 mm/dak.'dır. Üç boyutlu baskı esnasında iç dolgu \%6, dış yüzeylerin üst üste binme oranı $\% 15$, iç dolgu açıları \pm 45 derece ve tabakalar arası bağlantı her tabakada bir defadır. Üretilen test parçası teknik çizim STL dosyası Grafik 2.1.1'de verilmiştir.

Grafik 2.1.1: Kaplama yapılacak 3 boyutlu basılmış test numunesi stl dosyası görüntüsü

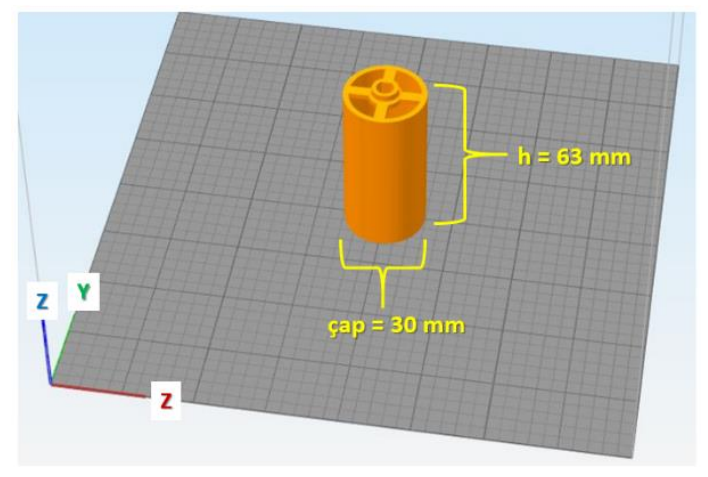

\section{2. Üç Boyutlu Yazıcı ile Üretilen Parçanın Kaplanması}

Üç boyutlu yazıcı ile üretilen silindirik numunelerin üç farklı toz (beyaz alümina, garnet ve cam küre) ile yüzeylerinin kaplanması işlemi için özel olarak motorize bir kaplama düzeneği üretilmiştir. Devir kontrollü bir elektrik motoru ile 3 boyutlu yazıcıyla üretilen silindirik numuneyi bağlayacak ve istenen hızda dönmesi sağlayacak bir bağlantı ayağı tasarlanmıştır. Tasarlanan bağlantı ayağına merkez eksende kendi etrafında dönebilecek şekilde yerleştirilen numunenin bir ucundan devir ayarlı motor bağlantısı gerçekleştirilmiştir. Oluşturulan motorize düzenek, kaplama yapılacak silindirik parçayla birlikte kaplama işlemi sırasında çevre 
şartlarından etkilenmemesi için cam bir fanus içine alınmıştır. Kaplamada kullanılan tozların yüzeye iyi yapışmasını sağlamak için motor devir ayarı optimizasyonu yapılmıştır. Optimizasyon sonrası kullanılan kaplama tozlarında motor devrinin 5 dev/dak. hız ile yüzeyde homojen bir dağılım ve yapışma gözlemlendiği için 5 dev/dak. kaplama esnasındaki döndürme hızı olarak seçilmiştir. Üretilen motorize kaplama düzeneği resmi Grafik 2.2.1 (a)'de verilmiştir. Motorize düzenek cam bir fanus içine alınarak 5 dev/dak. hızla döndürülmüştür. 3 boyutlu basılan test numunesinin yüzeyi, hazırlanan epoksi reçine ve sertleştirici karışımı (\%90 epoksi reçine; \%10 sertleştirici) bir firça yardımıyla kaplama yapılacak yüzeye sürülmüştür. Epoksi reçine ile yüzeyin ıslatılması işlemi Grafik 2.2.1 (b)'de görülmektedir.

Grafik 2.2.1: (a)Motorize yüzey kaplama uygulama düzeneği (b)epoksi reçine ile yüzeyin ıslatılması
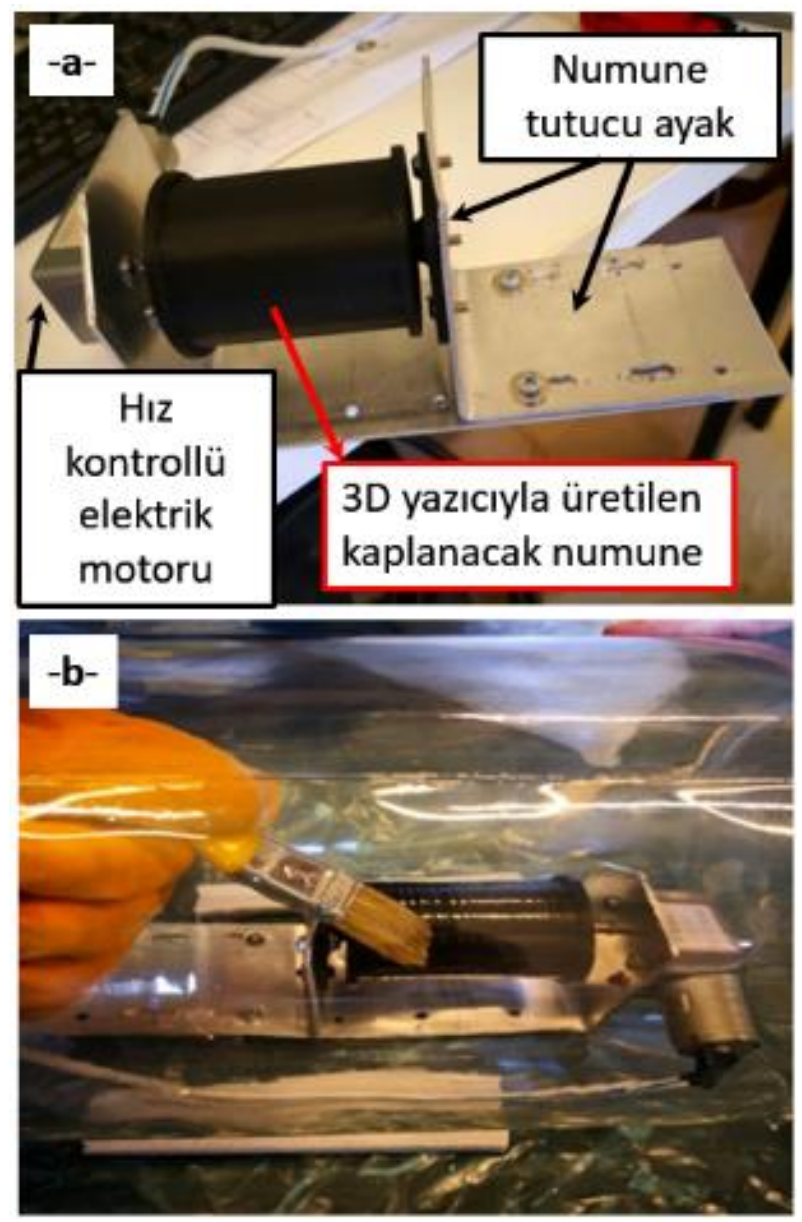

Üç boyutlu yazıcı ile üretilen numune yüzeyini kaplamak için 3 farklı yapıda toz kullanılmıştır. Bu tozlar beyaz alüminyum oksit, garnet ve seramik küredir. Yüzey kaplama malzemesi olarak bu tozların seçilmesindeki amaç; erozif aşınma direnci düşük olan 3 boyutlu yazıcıyla basılmış PLA malzemenin yüzey aşınma direncinin nasıl değiştiğini incelemektir. Gerçekleştirilen toz kaplama yöntemiyle altlık malzemesi haline gelen PLA numunenin erozif aşınmadan korunup korunamadığı araştırılmıştır. Toz ile kaplama yapılmış numunelerin erozif aşınma ve sonrasında yüzey pürüzlülüğüne etkilerini karşılaştırmak amacıyla; aynı aşınma testleri yüzeyi kaplanmamış PLA malzemeden üretilmiş numunelere de uygulanmıştır. Bununla birlikte 3 boyutlu yazıcılarda ikinci sırada en sık kullanılan malzeme olan Acrylonitrile Butadiene Styrene (ABS) malzeme ile üretilen kaplama yapılmamış numunenin de erozif aşınma testleri karşılaştırma yapmak amacıyla gerçekleştirilmiştir. ABS malzemenin yüzeyinde burada kullanılan kaplama tozlarının uygulanması gelecek çalışması olarak tasarlanmıştır. Yüzey kaplama malzemesi olarak kullanılan tozların özellikleri Tablo 2.2.1'de verilmiştir. 
Avrupa Bilim ve Teknoloji Dergisi

Tablo 2.2.1: Kaplama malzemesi olarak kullanılan beyaz alüminyum oksit, garnet ve seramik küre özellikleri

\begin{tabular}{|c|c|c|c|}
\hline Özellik & Beyaz Alüminyum Oksit & Garnet & Seramik Küre \\
\hline Tanecik Dağıllım Boyutu & $150-212 \mu \mathrm{m}$ & $90-150 \mu \mathrm{m}$ & $125-250 \mu \mathrm{m}$ \\
\hline Özgül Ă̆gırlı̆gl & $3,96 \mathrm{gr} / \mathrm{cm}^{3}$ & $4,1 \mathrm{gr} / \mathrm{cm}^{3}$ & $3.80 \mathrm{gr} / \mathrm{cm}^{3}$ \\
\hline Sertliği & 9 Mohs scale & 8 Mohs scale & $65 \mathrm{HRC}$ \\
\hline$\dot{I}$ I̧eriği & $\begin{array}{c}\mathrm{Al} 2 \mathrm{O} 3: \% 94.5-95.5 \\
\mathrm{SiO} 2: \% 0.50-0,80 \\
\mathrm{Fe} 2 \mathrm{O} 3: \% 0,30 \\
\mathrm{TiO} 2: \% 2,60-3,20 \\
\mathrm{CaO}+\mathrm{MgO}: \% 0,30\end{array}$ & $\begin{array}{c}\text { Al2O3: } 21 \% \\
\text { Fe2O3: } 31 \% \\
\text { SiO2: } 35 \% \\
\text { MgO: } 8 \% \\
\text { CaO: } 1,5 \% \\
\text { TiO2: } 1 \% \\
\text { P2O5: } 0,05 \% \\
\text { MnO: } 0,5 \% \\
\text { ZrO2: Eser Miktarda }\end{array}$ & $\begin{array}{l}\mathrm{ZrO} 2: \% 67 \\
\mathrm{SiO} 2: \% 31 \\
\mathrm{~A} 12 \mathrm{O} 3: \% 2\end{array}$ \\
\hline
\end{tabular}

\subsection{Erosiv Aşınma Testleri}

Katı partikül erozyonu testleri ASTM G76-95 standardına göre, Grafik 2.3.1'de şematik resmi görülen özel olarak tasarlanmış test kabini içinde gerçekleş̧irilmiş̧ir. Erozif aşınma testlerinde, aşındırıcı partikül olarak 60 mesh tane boyutu dağılımında $(212-300 \mu \mathrm{m})$ beyaz alümina oksit kullanılmıştır. Numune tutucuya sabitlenen test kuponları nozul püskürtme yönüne 90 derece açıyla duracak şekilde yerleştirilmiştir. 1.5 bar püskürtme basıncında, $50 \mathrm{~mm}$ uzunluğa ve $5 \mathrm{~mm}$ çıkış delik çapına sahip nozuldan aşındırıcı partiküller 10 saniye boyunca test numune yüzeylerine gönderilmiştir. 1.5 bar basınçta püskürtülen aşındırıcı taneciklerin hızları çift disk metoduyla $56 \mathrm{~m} / \mathrm{s}$ olarak ölçülmüştür. Aşındıııcı partiküllerin debisi 5,7 gr/s olarak hesaplanmıştır. Nozul çıkışı ile numune yüzeyleri arası mesafe $20 \mathrm{~mm}$ olarak ayarlanmıştı. Her numune test öncesi ve sonrası basınçlı hava ile temizlenerek testler sonrası hassasiyeti $\pm 0.1 \mathrm{mg}$ olan hassas terazi ile kütle kayıpları ölçülmüştür. Katı partikül erozyonu test parametreleri Tablo 2.3.1'de listelenmiştir.

Grafik 2.3.1: Katı partikül erozyonu test düzeneği

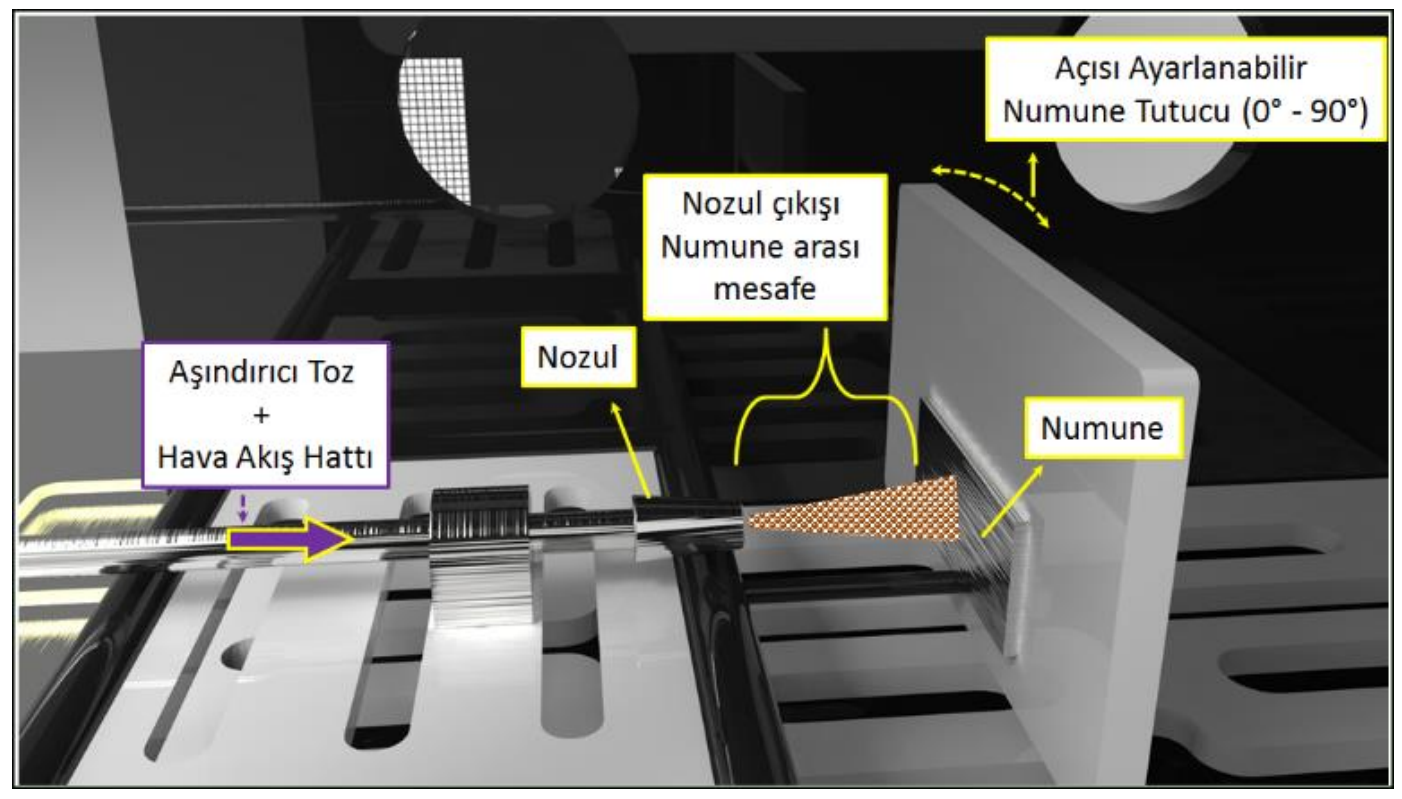


European Journal of Science and Technology

Tablo 2.3.1: Katı partikül erozyon testi parametreleri

\begin{tabular}{lc}
\hline \multicolumn{1}{c}{ Parametre } & Tanım / Değer \\
\hline Aşındırıcı tipi & $\mathrm{Al}_{2} \mathrm{O}_{3}$ \\
\hline Aşındırıcı tanecik boyut dağılımı & 60 mesh $(212-300 \mu \mathrm{m})$ \\
\hline Aşındırıcı çarpma açısı & $90^{\circ}$ \\
\hline Püskürtme Basıncı & $1.5 \mathrm{bar}$ \\
\hline Nozul çapı & $5 \mathrm{~mm}$ \\
\hline Aşındırıcı kütlesel debisi & $5,7 \mathrm{~g} / \mathrm{s}$ \\
\hline Aşındırıcı hızı & $56 \mathrm{~m} / \mathrm{s}$ \\
\hline Test sıcaklığı & $25^{\circ} \mathrm{C} \pm 2^{\circ} \mathrm{C}$ \\
\hline Test süresi & $10 \mathrm{saniye}$ \\
\hline Nozul çıkışı-numune arası mesafe & $20 \mathrm{~mm}$ \\
\hline
\end{tabular}

\subsection{Yüzey Pürüzlülük ve Hasar Analizi}

Erozif aşınma testleri önce ve sonrası, 3 boyutlu yazıcıyla üretilen kaplamasız ve kaplama yapılmış yüzeylerin karakterizasyonu temassız laser optik profilometre (Nanovea PS50, USA) yardımıyla gerçekleştirilmiştir. Toz kaplama işlemi öncesi yapılan profilometre taramaları ile 3 boyutlu basım ile üretilen parçaların yüzey pürüzlülük analizleri gerçekleştirilmiştir. Toz kaplama işlemi sonrası yapılan profilometre taramaları ile tozların yüzeyde tutunma miktarları ve toz partiküllerin yüzeyde dağılımları görüntülenerek dağılım histogramları elde edilmiştir. Katı partikül erozyon testleri sonrası ise ortaya çıkan erozyon krateri geometrisi, yüzeyde oluşan hasarın topografik 3 boyutlu görüntüsü ve hem alansal hem de çizgisel pürüzlülük değerleri elde edilerek irdelenmiştir. Alansal pürüzlülük ölçümlerinde temassız laser profilometre cihazı ISO 25178-2:2012 standardına göre analiz gerçekleştirmektedir. 3 boyutlu temassız laser profilometre taramaları ile ayrıca erozyon kraterinde ortaya çıkan hacimsel kayıp ve erozyon krateri alanı hesaplanmıştır. Pürüzlülük analizlerinde özel bir yazılım olan Mountains ${ }^{\circledR}$ (surface imaging \& metrology software,FR) kullanılmıştır. Alansal pürüzlülük taramaları kullanılarak ayrıca çizgisel pürüzlülük analizleri de ISO 4287:1997 standardına göre gerçekleştirilmiştir.

\section{Araştırma Sonuçları ve Tartışma}

\subsection{Katı Partikül Erozyonu}

Tipik aşınma türlerinden biri olan katı partikül erozyonu, aşındırıcı partiküllerin hedef malzeme yüzeyine tekrarlı şekilde çarparak malzemeden ciddi miktarda kayıplara sebep olan bir süreçtir (Zhou et al., 2013). Katı partikül erozyonu sonucu yüzeyde oluşan hasarların etkilendiği birincil faktörlerden bir tanesi, hedef malzeme yüzeyi ile aşındırıcı partiküller arasındaki etkileşimdir. Katı partikül erozyonu dayanımını artırmak amacıyla; malzemelerin yüzeyleri ısıl işlem, yüzey sertleştirme, boya ve özel kaplama uygulamaları gibi yöntemlerle yüzey en iyileştirmeleri yapılmaya çalışılmaktadır. Yapılan bu çalışmada ise, altlık malzeme olarak kullanılan 3 boyutlu yazıcı ile üretilmiş PLA malzemenin yüzeyi farklı özellikte tozlarla kaplanarak yüzey erozif aşınma dayanımı artırılmaya çalışılmıştır. PLA numunelerin yüzeyleri beyaz alüminyum oksit, seramik küre ve garnet tozlarıyla kaplanarak erozif aşınma testleri gerçekleştirilmiştir. Kapalamaların etkisini incelemek amacıyla da kaplamasız olarak üretilen PLA ve ABS numunelerin erozif aşınma testleri de gerçekleştirilmiştir. 3 farklı toz ile yapılan kaplama işlemi sonrası tozların yüzeyde dağılma haritasını çıkarmak ve yüzeye yapışma karateristiklerini ortaya koymak amacıyla temassız lazer profilometre ile yüzey taramaları yapılmıştır. Yapılan yüzey tarama sonuçları Grafik 3.1.1'de verilmiştir. Yapılan analizlerde beyaz alüminyum oksit toz kaplamada yüzeye yapışan partiküllerin boyut dağılımının 50 ile $1000 \mu \mathrm{m}$ arasında değiştiği gözlemlenirken; en fazla sayıda (yaklaşık 1500 adet) toz partikülünün $320 \mu \mathrm{m}$ tanecik boyutuna sahip olduğu gözlemlenmiştir. Seramik küre ile yapılan kaplamada partiküllerin 150-400 $\mu$ m arası tanecik büyüklüğü dağılımı gösterdikleri gözlemlenmiştir. Ortalama $300 \mu \mathrm{m}$ tanecik boyutundaki seramik küre tanelerinin sayısının 100 adet civarı gerçekleştiği görülmüştür. Yapılan yüzey kaplama toz analizi irdelemelerinde bahsi geçen tanecik büyüklüklerinin birebir kullanılan kaplama toz taneciklerinin boyutlarını değil, kaplama işlemi sonrası bu taneciklerin yüzeye yapışarak oluşturdukları kaplama tabakasındaki dağılımları ve öbeklenmelerin genel ortalamasını verdiğini belirtmek gerekir. Son olarak garnet tozlarıyla yapılan kaplama işlemi, 50$500 \mu \mathrm{m}$ arası tanecik boyut dağılımı gösterirken, ortalama 850 adet $200 \mu \mathrm{m}$ boyuta sahip taneciğin maksimum sayıya sahip olduğu gözlemlenmiştir. Grafik 3.1.1'de histogramların altında yer alan tozların dağılım haritaları kontur dağılımlarını vermektedir. Yüzey dağılım haritalarında beyaz aliminyum oksit tozların yüzeyde büyük bölgesel alanlarda toplanma gerçekleştirdiği gözlemlenmiştir. Profilometre ile gerçekleştirilen taramada $20 \mathrm{~mm}^{2}(5000 \times 4000 \mu \mathrm{m})$ alan taranmıştır. Profilometre taramalarının analizleri sonucu Grafik 3.1.1'de görülen yüzey dağılım haritasında $20 \mathrm{~mm}^{2}$ taranan alanın içinde beyaz alüminyum oksit tozların toplam $5.96 \mathrm{~mm}^{2}$ ( $\%$ 29.8 ); seramik kürelerin $6.38 \mathrm{~mm}^{2}$ ( \% 31.9 ) ve garnet tozların $6.18 \mathrm{~mm}^{2}$ ( \% 30.9 ) alan kapladığı bulunmuştur. Birbirine çok yakın toplam kaplama alanları içinde en yüksek değer seramik küreler ile elde edilmiştir. Seramik kürelerin tam küresel formda oluşları birbirine yapışarak öbekler oluşturmasını kolaylaştırıken, tozlar içinde keskin köşeli olmasına rağmen en küçük tanecik toz dağılım boyutuna sahip garnet ile yapılan kaplama da seramik kürelere çok yakın bir alan kaplayabilmiştir. En küçük alanın kaplanabildiği alümina tozlarında keskin köşeli olma ve tanecik boyutunun büyük olması etken faktörlerdir. 
Grafik 3.1.1: Ü̧̧ farkll toz ile kaplama sonrası yüzeydeki toz büyüklük dăğllm histogramlart ve yüzey dağgllım haritaları

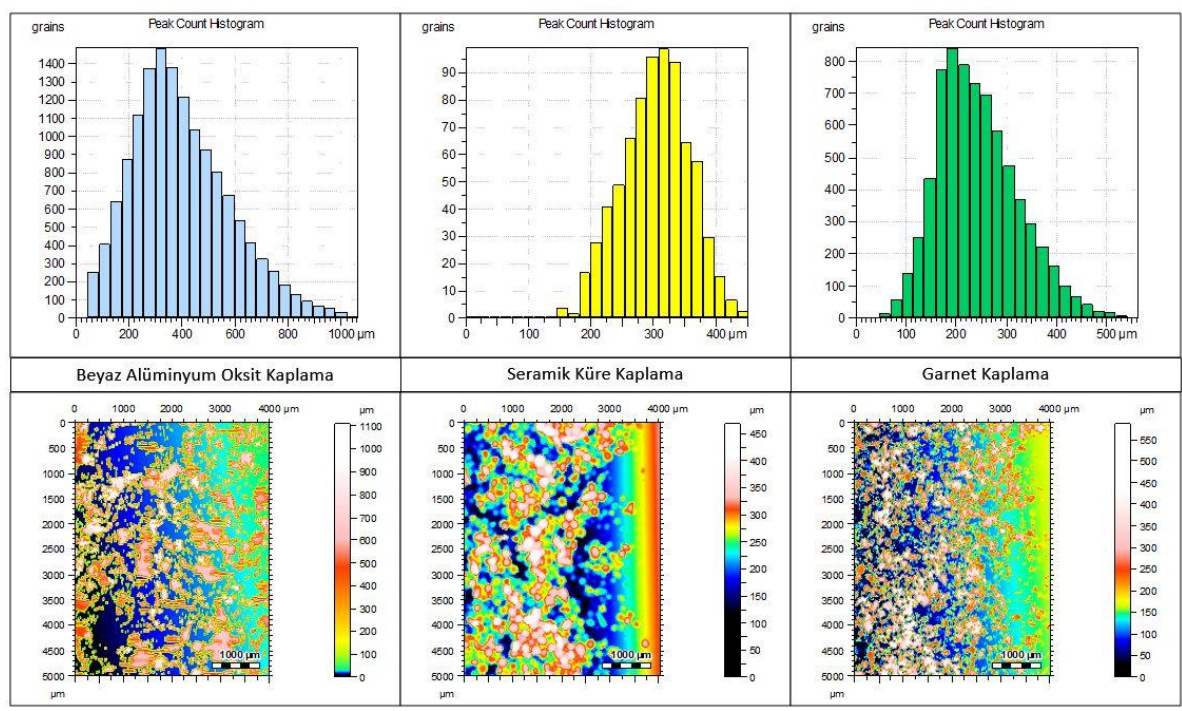

Katı partikül erozyon testleri sonrasında malzemede oluşan malzeme kaybı ve hasar miktarı, erozyon oranı tanımlamasıyla ve hesabıyla analiz edilir. Erozyon oranı; erozyon testi sonrası malzemede oluşan ağırlık kaybının (mg), erozyon testinde kullanılan toplam aşındırıcı partikül ağırlığına (g) bölünmesiyle elde edilir (Harsha \& Thakre, 2007) (Avcu et al., 2013). Birimi mg/g'dır. Grafik 3.1.2'de farklı 3 tür kaplama uygulanmış ve kaplamasız PLA ve ABS numunelerin erozyon oranları verilmiştir. Erozyon oranı değerleri çok küçük değerler olarak ortaya çıktığı için her sonuç $10^{5}$ ile çarpılarak genişletilmiştir. Erozyon oranları hesaplanırken, her bir numune için testler 3 kez tekrarlanmış, 3 tekrarın ortalaması alınarak grafik oluşturulmuştur. Tekrarlı testlerde standart sapma; değerin \% 3.2'si kadar olmuştur. Grafik 3.1.2'de, kaplamasız olarak erozif aşınma testleri gerçekleştirilen ABS ve PLA malzemelerden üretilmiş numunelerin erozyon oranları; ABS numune için $14.38(\mathrm{mg} / \mathrm{g}) * 10^{5}$; PLA numune için $-9.82(\mathrm{mg} / \mathrm{g}) * 10^{5}$ olmuştur. PLA malzemede erozif aşınma sonrası erozyon oranının negatif değerde çıkması, aşındıııı partiküllerin PLA malzeme yüzeyine saplanarak gömüldüklerinin göstergesidir. Sünek malzemelerin karakteristik özelliklerinden biri olan hedef malzeme yüzeyine gömülme mekanizması PLA malzemede de gerçekleşmiştir. Kaplama yapılan numuneler içinde en düşük aşınma oranı garnet tozuyla kaplanmış numunelerde $302.98(\mathrm{mg} / \mathrm{g}) * 10^{5}$, en yüksek erozyon oranı ise $368.77(\mathrm{mg} / \mathrm{g}) * 10^{5}$ olarak gerçekleşmiş̧ir. Kaplamasız numunelerde çok daha düşük ortaya çıkan aşınma oranları, kaplama işleminin erozyon aşınma davranışını iyileştirmekten ziyade kötüleştirdiği sonucunu ortaya koymuştur. Diğer taraftan, kaplamalı numunelerde ortaya çıkan kütle kayıpları malzeme yüzeyine kaplanan tozların yerinden çıkarak ayrılması sonucu oluşmaktadır. Altık malzemeyle aşındırıcı partiküllerin teması ancak kaplama tozlarının yerlerinden çıktıktan sonra gerçekleşmektedir. Erozif aşınma testleri sonucu malzeme yüzeyinde oluşan hasar bölgesi pürüzlülük değerlendirmesi ve 3 boyutlu yüzey topografya analizleri pürüzlülük incelemelerinde irdelenmiştir.

Grafik 3.1.2: Erozif aşınma testleri sonrası ortaya çıkan erozyon oranları

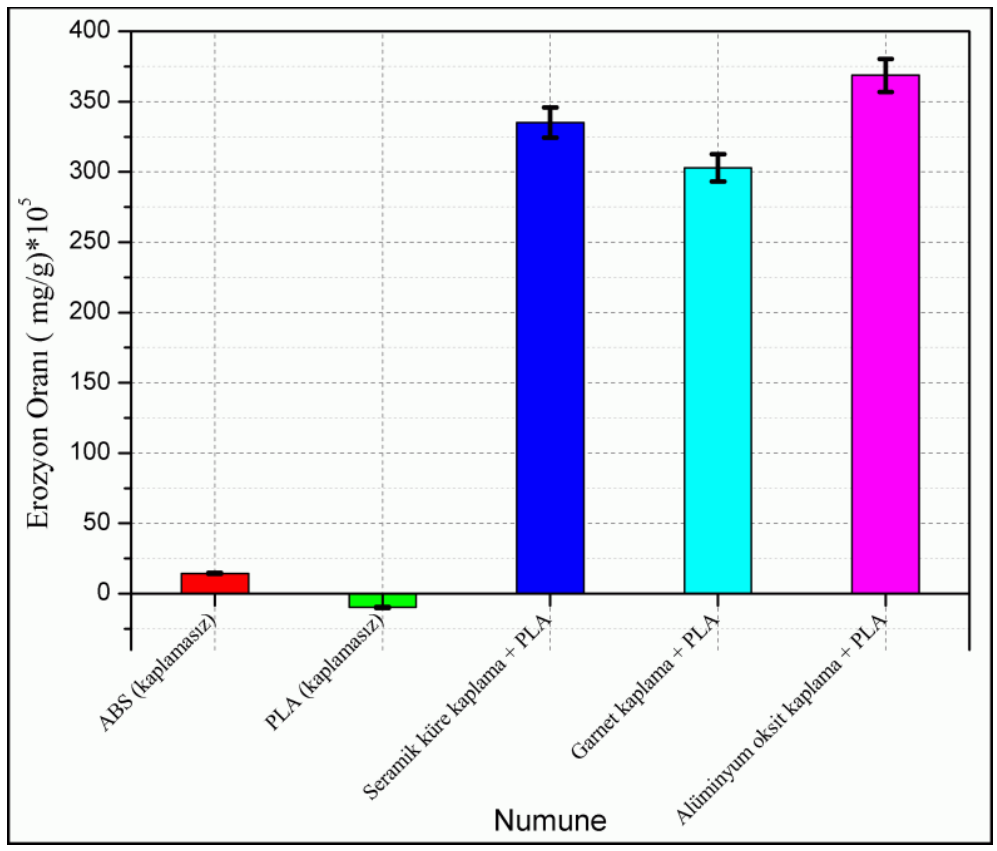

\subsection{Yüzey Pürüzlülük Analizi}


Yüzey pürüzlülüğ̈̈nün mekanik parçanın kullanılabilirliği ve uyumluluğu üzerinde büyük etkileri vardır (Enhui, Jian, Yan, \& Hongjing, 2019). Aynı zamanda üretilmek istenen parçaların yüzeyinde elde edilmek istenen pürüzlülük değeri; parçanın üretim maliyeti, üretim yöntemi ve kullanılan yöntem, kalite kontrolü gibi faktörler üzerinde birinci dereceden etkiye sahiptir. Herhangi bir yüzey pürüzlülüğü incelemesi, ölçümle başlamalı ve herhangi bir faydalı pratik amaca uygulanmadan önce ölçümleri karakterize ederek devam etmelidir (Thomas, 2014). Böylece genel kabul gören kural olan üç bölüme ayrarak (ölçüm, karakterizasyon ve uygulama) yüzey incelemesi gerçekleştirilir (Thomas, 2014). Yüzey pürüzlülüğü, malzemelerin yüzeylerinde ortaya çıkan nominal profilden artı ve eksi yönde olan yüzeysel sapmalar şeklinde tanımlanabilir. Yüzey pürüzlülüğünde, çizgisel bir hat üzerinden profilometre taraması yapılarak ortaya çıkan yüzey sapmalarının ortalaması alınarak yapılan ölçüm sonucu bulunan değer ortalama pürüzlülük $\left(\mathrm{R}_{\mathrm{a}}\right)$ olarak isimlendirilir. Diğer taraftan temassız profilometrelerin gelişimiyle alansal yüzey taramaları da gerçekeleş̧irilerek alansal ortalama pürüzlülük değeri de $\left(\mathrm{S}_{\mathrm{a}}\right)$ bulunabilir ve görüntülenebilir hale gelmiştir. $\mathrm{Bu}$ çalışmada, daha sonra üzerine kaplama uygulanacak parçalar ABS ve PLA malzemeden imal edilmiş ve imalat sonrası kaplama yapılmadan her iki malzemeden üretilmiş silindirik parçaların yüzey pürüzlülük değerleri, profilometre yardımıyla taranarak yüzey pürüzlülükleri analiz edilmiştir. Grafik 3.2.1'de ABS ve PLA malzemeden imal edilmiş altlık silindirik parçaların, lazer profilometre ile taraması sonrası ortaya çıkan 3 boyutlu yüzey pürüzlülük görüntüsü verilmiştir. Her iki malzemenin yüzeyinden taranan $20 \mathrm{~mm}^{2}$ alanda pürüzlülüğe bağlı oluşan maksimum yükseklik farkı $\left(\mathrm{S}_{\mathrm{z}}\right)$, ABS malzemede 695 $\mu \mathrm{m}$ olurken PLA malzemede bu değerin $247 \mu \mathrm{m}$ olduğu ortaya çıkmıştır. $S_{z}$ değeri; malzemenin normal yüzey eksenine göre; en üst noktadaki tepe uç noktası ile en dip noktadaki çukur uç noktası arası oluşan dikey mesafeyi tanımlar. ABS malzeme yüzeyinin aritmetik ortalama pürüzlülük $\left(\mathrm{S}_{\mathrm{a}}\right)$ değeri kontrol alanında $52.9 \mu \mathrm{m}$; PLA malzeme için ise $\mathrm{S}_{\mathrm{a}}$ değeri aynı koşullarda $37.9 \mu \mathrm{m}$ olarak ölçülmüştür. Bu sonuca göre, 3 boyutlu yazıcı ile üretimde, PLA malzeme kullanıldığında ABS ile üretime göre $\% 28,3$ daha düşük yüzey pürüzlülüğü yani bir başka deyişle daha iyi yüzey kalitesi elde edilmiştir. PLA ve ABS hammaddeleri için oluşan yüzey kalitesi farkının, birbirinden farklı 3 boyutlu üretim parametrelerinden ortaya çıktığı değerlendirilmiştir. ABS ve PLA ile baskı sırasında farklı nozul ssıtma derecesi, ilerleme ve baskı hızları kullanılmaktadır.

Grafik 3.2.1: 3D printer ile kaplama için hazırlanan silindirik parçaların 3 boyutlu yüzey profilometre görüntüleri (a) ABS (b) PLA malzemeden üretilmiş

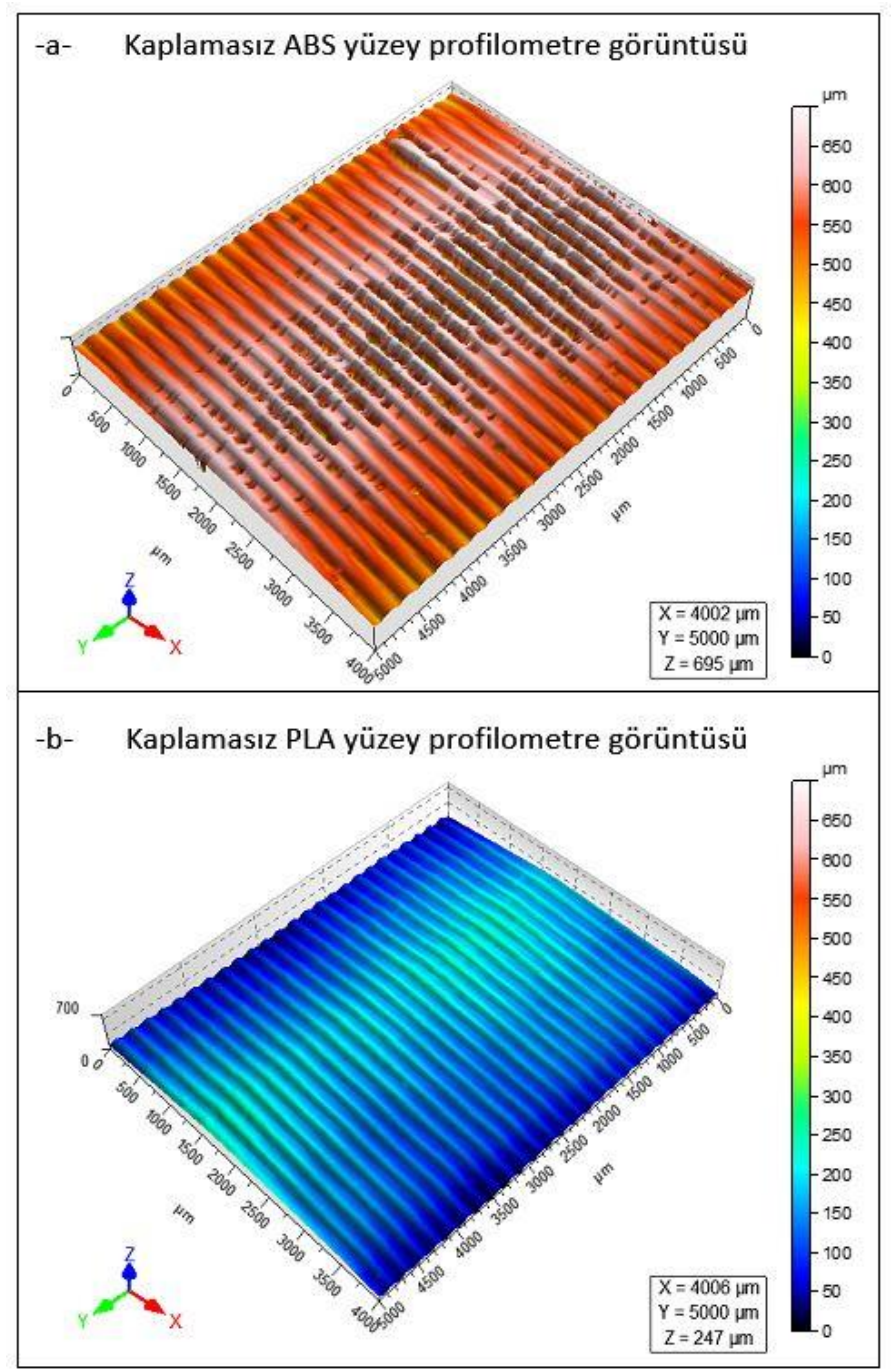

Eroziv aşınma sonrası kapalamasız ve üç farklı toz ile kaplanmış numunelerin yüzeyleri 3 boyutlu profilometre ile taranarak yüzey pürüzlülük haritası çıkarılmış ve Grafik 3.2.2'de verilmiştir. Profilometre taraması $20 \mathrm{~mm}^{2}$ alanda gerçekleştirilmiştir. Tarama yapılan alan, eroziv aşınma testleri sonrası ortaya çıkan erozyon kraterinin merkezi başlangıç noktası seçilerek çevreye doğru genişletilmiştir. Böylece eroziv aşınma testlerinde, nozul püskürme konisinin içinde aşındırıcı partiküllerin yüzeyde ortaya çıkardıkları hasarlar 3 
boyutlu olarak ortaya konabilmiştir. Alansal pürüzlülük incelemesinde aritmetik ortalama pürüzlülük $\left(\mathrm{S}_{\mathrm{a}}\right)$ değeri olarak kaplamasız 3 boyutlu basılmış malzemelerden PLA ile üretilmiş parça yüzeyinde $36.1 \mu \mathrm{m}$ değeri ölçülürken, ABS ile üretilen numue yüzeyinde eroziv aşınma sonrası ölçümlenen $S_{a}$ değeri $32.1 \mu$ m olmuştur. Bu değerin PLA numunede \%11 daha yüksek çıkması sadece aşınma sonucu oluşan yüzey pürüzlülüğüne değil, aynı zamanda Grafik 3.2.2 (a)'da görüldüğü üzere 3 boyutlu basım esnasında PLA malzeme arakatlarında oluşan izlere de bağlıdır. Toz kaplama yapılan numunelerde eroziv aşınma sonrası ortaya çıkan $S_{a}$ değerleri ise sırasıyla alümina oksitle kaplanmış yüzeyde $42.4 \mu \mathrm{m}$ (Grafik 3.2.2 (c)); seramik küre kaplanmış yüzeyde $104 \mu \mathrm{m}$ (Grafik 3.2 .2 (d)) ve garnet kaplanmış yüzeyde $43 \mu \mathrm{m}$ (Grafik 3.2.2 (e)) olmuştur. $\mathrm{S}_{\mathrm{a}}$ değeri sermik küre ile kaplanmış yüzeyde belirgin şekilde yüksek çıkmıştır. Grafik 3.2.2 (d) incelendiğinde yüzeyde çok fazla sayıda batma ve yerinden çıkma izinin olduğu görülmektedir. Sermaik küre tozlar tam küresel geometriye sahiptirler. Alumina aşındırıcı tozların yüzeyde bulunan seramik kürelere çarpması sonucu sermik kürelerin parçalanarak kaplama yüzeyinden ayrıldığı ve yerinden çıkmaları sonucu Grafik 3.2.2 (d)'de net şekilde görülen oyukların $S_{a}$ değerini artırdığı gözlemlenmiştir. Diğer taraftan, bir başka ilginç sonuç alüminyum oksit tozla kaplanmış numune yüzeyinde gözlemlenmiştir Grafik 3.2.2 (c). En düşük $\mathrm{S}_{\mathrm{a}}$ değeri $42.4 \mu \mathrm{m}$ olarak alümina oksitle kaplanmış numune yüzeyinde oluşurken aynı zamanda en yüksek erozyon oranı da bu numunede ortaya çıkmıştır (Grafik 3.1.2). Grafik 3.2.2 (c) incelendiğinde, eroziv aşınmaya bağlı bölgesel derin batma ve toz kaplamada kullanılan partiküllerin yerinden çıkması yüzeyde az sayıda gözlemlenmiştir. Buna bağlı olarak $S_{a}$ değeri düşük çıkmıştır. Diğer taraftan, aşındırıcı partiküllere maruz kalan kaplanmış yüzeyin tamamında malzeme kaybı gözlemlenmiş, buna bağlı olarak erozyon oranı diğer tozlarla kaplama yapılmış numunelerden daha yüksek olmuştur.

Grafik 3.2.2: Eroziv aşınma sonrası 3 boyutlu yüzey pürüzlülüğü görüntüleri (a) kaplamasız PLA yüzeyi (b) kaplamasız ABS yüzeyi (c) alümina oksit kaplanmış PLA yüzeyi (d) seramik küre kaplanmış PLA yüzeyi (e) garnet kaplanmış PLA yüzeyi

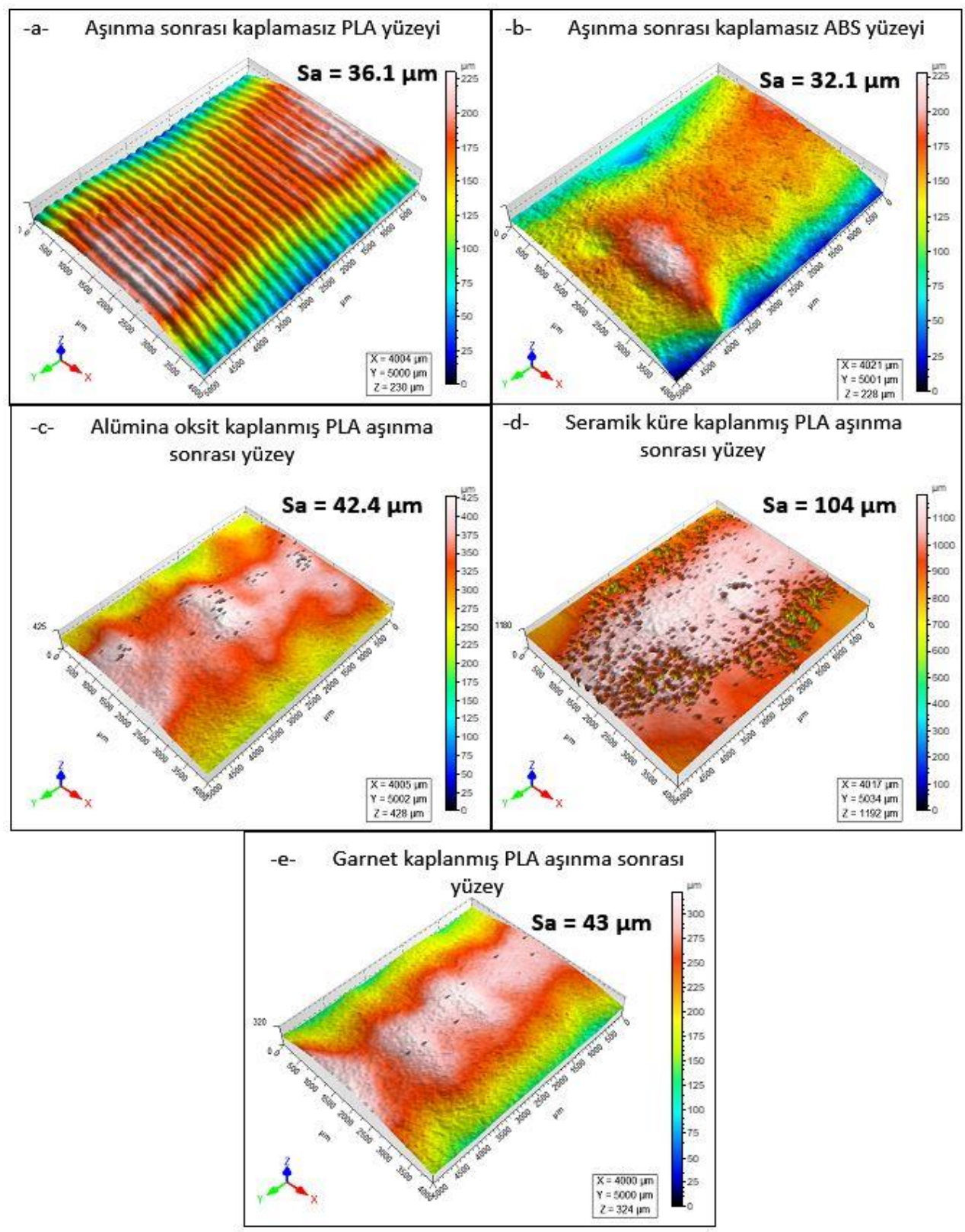

\section{Sonuç}


3D yazıcı ile üretilen silindirik deney numunelerinin yüzeyi farklı 3 toz ile kaplanarak (alümina oksit, seramik küre ve garnet) sonrasında eroziv aşınma testleri yapılmıştır. 3D baskı yöntemiyle üretilen parçaların zorlu şartlar altında servis ömürlerini uzatmak amacıyla yapılan toz kaplama işlemi sonrası, erozyon testlerinde en fazla erozyon oranı alüminyum oksit toz ile kaplanan PLA parçada gözlemlenirken en düşük erozyon oranı garnet ile kaplanmış PLA numunede gözlemlenmiştir. Kaplamasız 3D yazıcı ile üretilen PLA ve ABS malzemelerde, ABS malzemede erozyon oranı pozitif gerçekleşirken (aşınma gerçekleşmiş); PLA malzemede negatif erozyon oranının ortaya çıkması aşındırııı partiküllerin malzemeye gömülerek saplandığının ve kütle artışına sebep olduğunun göstergesidir. ABS malzemede aşındırıcı partiküllerin yüzeye gömülme yapmamalarının sebebi malzemnin 3D basım sonrası daha sert yüzey özelliği kazanarak PLA malzemeye göre daha gevrek yapı göstermesidir.

Diğer taraftan, eroziv aşınmaya maruz kalmış toz kaplanmış yüzeylerin yüzey pürüzlülükleri analzi edildiğinde en yüksek pürüzlülük değeri seramik küre toz ile kaplanmış numune yüzeyinde ortaya çıkmış, en düşük pürüzlülük değeri ise alümina oksit toz ile kaplanmış numune yüzeyinde gözlemlenmiştir.

\section{Kaynakça}

Avcu, E., Fidan, S., Bora, M. Ö., Çoban, O., Taşkiran, İ., \& Sinmazçelik, T. (2013). Solid Particle Erosive Wear Behavior of Glass Mat Reinforced PPS Composites: Influence of Erodent Particle Size, Pressure, Particle Impingement Angle, and Velocity. Advances in Polymer Technology, 32(S1), E386-E398. https://doi.org/10.1002/adv.21286

Bhaduri, D., Penchev, P., Batal, A., Dimov, S., Soo, S. L., Sten, S., ... Dong, H. (2017). Laser polishing of 3D printed mesoscale components. Applied Surface Science, 405, 29-46. https://doi.org/10.1016/j.apsusc.2017.01.211

Enhui, L., Jian, L., Yan, X., \& Hongjing, Q. (2019). The influences of light source and roughness ranges on colour image-based visual roughness measurement performance. Measurement, 147, 106855. https://doi.org/10.1016/j.measurement.2019.106855

Harsha, a. P., \& Thakre, A. a. (2007). Investigation on solid particle erosion behaviour of polyetherimide and its composites. Wear, 262(7-8), 807-818. https://doi.org/10.1016/j.wear.2006.08.012

Kumar, R., Antonov, M., Beste, U., \& Goljandin, D. (2020). Assessment of 3D printed steels and composites intended for wear applications in abrasive, dry or slurry erosive conditions. International Journal of Refractory Metals and Hard Materials, 86, 105126. https://doi.org/10.1016/J.IJRMHM.2019.105126

Lanzetta, M., \& Sachs, E. (2003). Improved surface finish in 3D printing using bimodal powder distribution. Rapid Prototyping Journal, 9(3), 157-166. https://doi.org/10.1108/13552540310477463

Thomas, T. R. (2014). Roughness and function. Surface Topography: Metrology and Properties, 2(1). https://doi.org/10.1088/2051$672 X / 2 / 1 / 014001$

Zhou, L. Y., Zhang, H., Pei, X. Q., Friedrich, K., Eger, C., \& Zhang, Z. (2013). Erosive wear of transparent nanocomposite coatings. Tribology International, 61, 62-69. https://doi.org/10.1016/j.triboint.2012.11.021 